\title{
Efficacy of Posture Awareness and Neck Exercise Program on Reducing Cervical Pain Among Elderly Patients at Assiut University Hospital, Egypt
}

\author{
Aml Hamdi Mahmoud ${ }^{1}$, Nermeen Mahmoud Abd El- aziz ${ }^{2}$, Safaa Ali Gamal El- deen ${ }^{3}$ \& Hanaa Moukhtar \\ Ibrahim ${ }^{4}$. \\ 1. Demonstrator of Gerontological Nursing, Faculty of Nursing, Assiut University, Egypt. \\ Assistant professor of Gerontological Nursing, Faculty of Nursing, Assiut University, Egypt. \\ 3. Assistant professor of Rheumatology \& Rehabilitation, Faculty of Medicine, Assiut University, Egypt. \\ 4. Lecturer of Gerontological Nursing, Faculty of Nursing, Assiut University, Egypt.
}

\begin{abstract}
Cervical pain is a common condition in the elderly population. It affects the physical health status in persons over 65 years and interferes with their daily activities. Study Aim: Evaluate the efficacy of posture awareness and neck exercise program on reducing cervical pain among elderly patients. Subject \& method: Quasi-experimental research design was used. The study was conducted in outpatient clinic of Rheumatology and Rehabilitation Department at Assiut University Hospital. The total sample size was 189 elderly. Two tools were used. The $1^{\text {st }}$ tool: An interview sheet including personal characteristics, medical history and elderly knowledge, the 2nd tool: The Northwick Park Neck Pain scale and jury were done by 3 expertise in erotological nursing. Results: The present study showed that the majority of studied patients aged $(60-<65)$ years, with mean age $62.48 \pm 3.43$ and there was a highly significant difference between pre and post-program of both isometric neck exercises and good neck posture $(\mathrm{p}=0.0001)$. Conclusion: It was concluded that isometric neck exercises and good neck posture are effective in the management of neck pain in elderly population. Recommendation: Implementation of isometric exercise and good neck posture among elderly population should be expanded as a community based intervention.
\end{abstract}

\section{Keywords: Cervical Pain, Elderly, Isometric Exercise \& Neck Posture.}

\section{Introduction}

The total population in Egypt was 100,995.147 million at the mid of October 2019, 5.95\% of them was 65 years and older. Furthermore, life expectancy in Egypt had increased in 2019 to become 71.90 years (68.2 years for male and 73.0 years for female) (Central Intelligence Agency, 2019).

With aging degeneration occurs, bone spurs forms and the discs slowly shrink at the cervical and lumber spine. One feature of the degeneration is that the edges of the vertebrae often develop small, rough areas of bone called osteophytes; these changes may affect the ligaments and the stability of the spine. This could cause change of the spine and associated compression on nerves and blood vessels which will lead to cervical pain (McDonnell \& Lucas, 2012). Neck pain is common symptoms in elderly persons and $10-20 \%$ of persons over 60 reports moderate or severe neck pain on a monthly basis. Overall, older women report more neck pain than older men so that altering or diminishing physical activities and seeking of treatment due to neck pain are relatively common in the elderly person (Geiger \& Devereaux, 2017). Most cases of neck pain have a postural component as part of the underlying problem. In such cases, recognizing and understanding poor posture can play an important role in finding neck pain relief. Neck pain can be caused by several factors: poor posture, injury, degeneration of the bones, or illness. If the cause is an injury or poor posture, strengthening the neck can help with the pain and reduce the risk of future injury (Pillastrini et al., 2016).

An isometric exercise is a form of exercise involving the static contraction of a muscle without any visible movement in the angle of the joint. This includes static flexion, static extension and lateral flexion of neck holding in each position for 8 seconds by restricting movement of head which would be repeated 10 times for duration of 6 minutes (Jayabal, 2018). Isometric exercise is more effective in reducing neck pain, improving function and increasing active range of neck movements (Khan et al., 2014).

Gerontological nurses have an important role in relieving pain and enhance patients' quality of life so that they may engage in their activities of daily living to the maximum of their ability without being hampered by pain and related issues (Glowacki, 2015), that could be done by adding a regular exercise into the elderly routine lifestyle. Elderly persons are more likely to listen to their health care team rather than anyone else when it comes to their health decisions (Pascucci et al., 2012). 


\section{Significance of the study}

Neck pain is one of the most common musculoskeletal disorders in modern societies. It is estimated that approximately $67 \%$ of people in Iran have experienced neck pain at least once in their life. Neck pain is more prevalent in elderly and can lead to severe disability in 5\% of patients in Finland (Azadi, et al., 2019).

Neck pain is a considerable health problem for individuals of all ages. Approximately $20 \%$ of individual aged 60 years and older experience neck pain in a monthly basis in America, among this population neck pain is associated with other health complaints and poorer self-rated health (Maiers et al., 2014). In Egypt, approximately $85 \%$ of individuals over 60 years of age have some degree of disc degeneration that may lead to cervical pain (Ali, 2015).

\section{Study aim}

To evaluate the efficacy of posture awareness and neck exercise program on reducing cervical pain among elderly patients.

\section{Study hypothesis}

- There was lack of elderly knowledge about importance of good neck posture and isometric neck exercise.

- Neck posture and isometric neck exercise help to reduce cervical pain in elderly patients.

\section{Subjects \& Methods}

\section{Research design}

Quasi-experimental research design was used.

\section{Setting}

The study was conducted in outpatient clinic of Rheumatology and Rehabilitation Department at Assiut University Hospital because this place had high flow rate of elderly patients with cervical pain.

\section{Sample}

sample size calculates through using Epi/Info Version 3 with confidence level $90 \%$, according to the prevalence rate during year (2018) the total number of patients was 624. The total sample number in this study was 189 patients selected by convenient sample.

Study tools: data collected using 2 tools

Tool I: Interviewing questionnaire: consisted of three parts:

Part I: It includes socio-demographic characteristics as, age, sex, residence, marital status, occupation, and level of education.

Part II: It includes elderly medical history such as presence of chronic diseases or health problem as hypertension, diabetes, cardiovascular disease.

Part III: It includes assessment of elderly knowledge about good neck posture and isometric neck exercise as definition, importance and steps of this exercise.
Scoring system regarding knowledge

The total number of knowledge questions was 15 list questions. Each correct answer was given one score and zero score for the wrong answer. The total scores were 15 degrees. Equal and more than 50\% were considered satisfactory level and less than $50 \%$ was considered unsatisfactory.

Tool II: The Northwick Park Neck Pain Questionnaire (NPQ)

It is used to measure neck pain. This questionnaire has been designed to give information about how neck pain affected the ability to manage in everyday life. It contains nine items, pain intensity, pain and sleeping, numbness in arms at night, duration of symptoms, carrying, reading and watching TV, working / house work etc., social activities and driving (if applicable)

Scoring system

Each item in the Northwick Park Neck Pain Questionnaire (NPQ) is rated out of four, with "0" representing no neck pain and "4" representing severe neck pain. NPQ scores are used to categorize pain: no neck pain (0-24\%), mild (25-49\%), moderate (5074\%), and severe (75-100\%) (Leak et al., 1994).

Validity and reliability of tools

Tools tested for its content validity by group of three expertise in gerontological nursing. The required modifications were done. Internal consistency was assessed by using Alpha Cronbach's test and it was (Cronbach's $\alpha=0.86$ ). (Aguirre et al, 2013)

Good neck posture and isometric neck exercise program

The good neck posture and isometric neck exercise program were developed by the researchers, revised and corrected. This program was applied to all participants individually. The program aimed at evaluates the efficacy of posture awareness and neck exercise on reducing cervical pain among elderly patients. The program consisted of two parts: 1) Awareness part, 2) Practical part

\section{Program parts}

1. Awareness part

- Age related changes occurring in muscle, bone, joint and intervertebral discs in the cervical spine...etc.

- Definition, importance and steps of the isometric neck exercise for elderly...etc.

- A patient was educated about the importance of maintaining good neck posture and advised to maintain it all over the day.

2. Practical part

1. Isometric neck Exercise, which include static flexion, extension, and lateral flexion of neck holding in each position for 8 seconds by restricting movement of head which would be repeated 10 times for duration of 6 minutes and 
it should be done twice daily for 3 month (Jayabal, 2018). And this was done by using wristwatch and was calculated the time by restricting movement of head for 8 second and repeated 10 times in each position and the total duration was 6 minutes. Also the patients were taught how to do that exercise.

2. Patients were taught how to apply steps of good neck posture.

\section{Methods \\ Preparatory phase}

An official letter approval was obtained from the Dean of the Faculty of Nursing, to the director of Assiut University Hospital and to the head of Rheumatology and Rehabilitation department. This letter includes a permission to carry out the study and explained the aim and nature of the study. Oral consent was taken from the elderly after explanation the aim of the study.

\section{A pilot study}

was conducted on $10 \%$ of elderly in a selected setting to examine the applicability, the feasibility and clarity of the developed tools and the necessary modifications were done in data collection.

\section{Implementation phase}

Assessment of every elderly person in the study was done using all study tools (Pretest). Based on the findings of the assessment, the isometric neck exercise and good neck posture program were implemented on the elderly that hadn't practice any neck exercise. The developed isometric neck exercise program was conducted in three session for each elderly patients ( 1 session for theory and 2 session for practice), the patient was taught to do the exercise at home twice daily for 3 month and the patient was followed once weekly after session implementation. Also patients were followed up on as regards attaining good posture in most of the day. Compliance of the patients was checked through calling them by phone.

\section{Data Collection}

The study started in first of June 2019 and ended at the mid of December 2019; data was collected from the previous mentioned setting for seven months. The researcher collected data two days per week, 4 hours each day from 9 am to $1 \mathrm{pm}$, and the number which was interviewed was 4-5 elderly patients per day. And for each patient the time of session ranges between 60- 75 minutes. The interviewer selected patients who fulfilled the criteria.

\section{Exclusion criteria}

- Patients received physiotherapy interventions on the neck within 6 month before enrollment.

- Patients with end stage organ failure.

- Patients with cognitive impairment who will not be able take active port in the study.

- Patients with neurological impairment or physical disability that interfere with their participation in the study.

- Patients diagnosed with cervical disc or myelopathy.

- Patients with uncontrolled medical conditions.

\section{Evaluation phase}

It was carried out in two phases, the $1^{\text {st }}$ time before program intervention (pre-test) and the $2^{\text {nd }}$ time after three month from program implementation (post-test).

\section{Ethical consideration}

Research proposal was approved from ethical committee in the faculty of Nursing Assiut University. There was no risk for study subject during application of the research. The study was following common ethical principles in clinical research. Written consent was obtained from director of each place and oral from the patients that were willing to participate in the study, after explaining the nature and purpose of the study. Confidentiality and anonymity were assured. Study subject had the right to refuse to participate or withdraw from the study without any rational at any time. Study subject privacy was considered during collection of data.

\section{Statistical analysis}

The data obtained had reviewed, prepared for computer entry, coded, analyzed and tabulated. Descriptive statistics (frequencies and percentages, mean and standard deviation, etc.) were done using computer program (SPSS) version (22). Independent sample T-test and, Chi-square tests used in the relationship between both groups'. It's considered significant when P.value less than (0.05). 


\section{Results}

Table (1): Socio- demographic characteristics of the studied elderly patients in outpatient clinic of Rheumatology and Rehabilitation Department at Assiut University Hospital 2019, (N: 189).

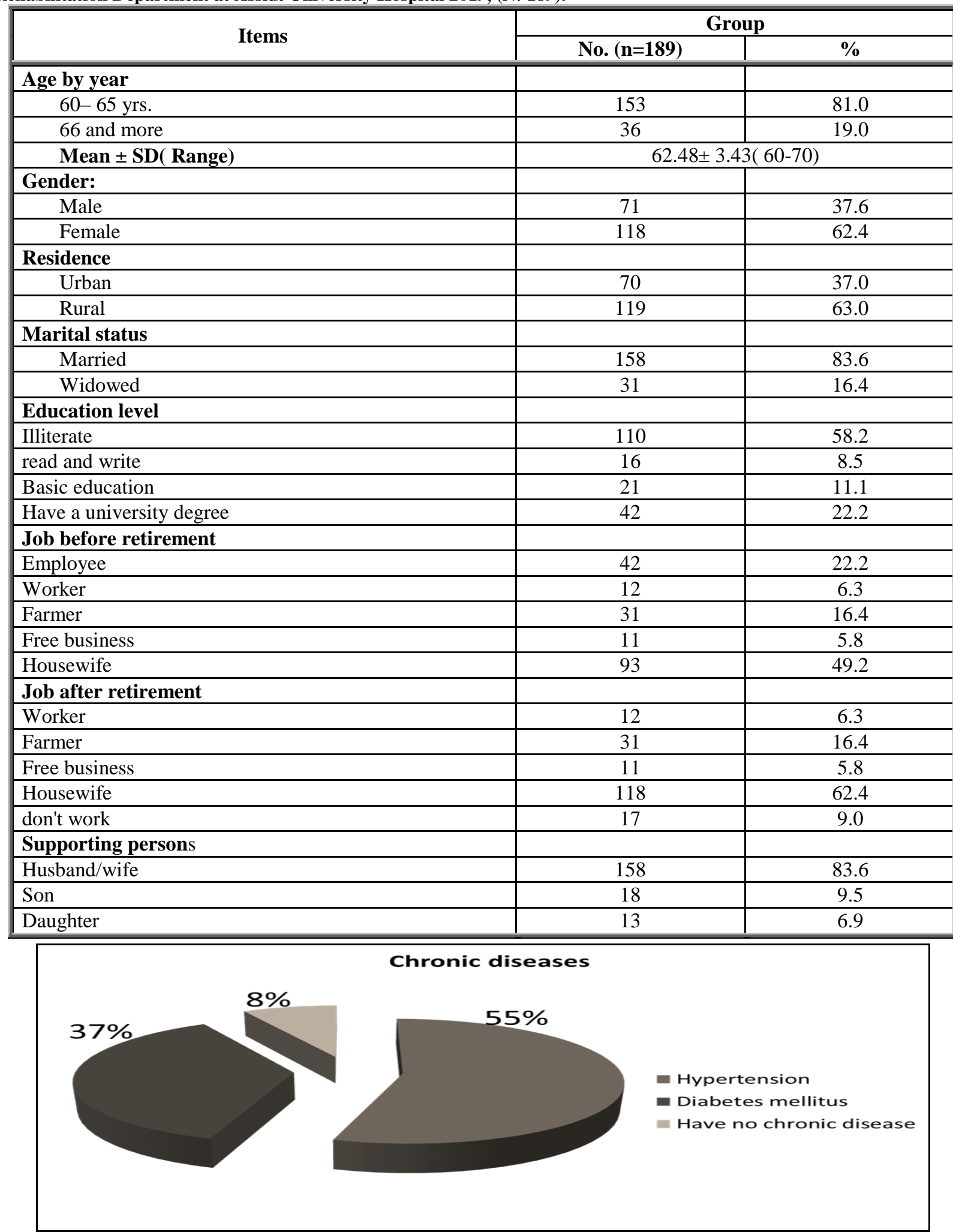

Figure (1): Distribution of studied elderly patients related to medical history in outpatient clinic of Rheumatology and Rehabilitation Department at Assiut University Hospital 2019, (N: 189). 


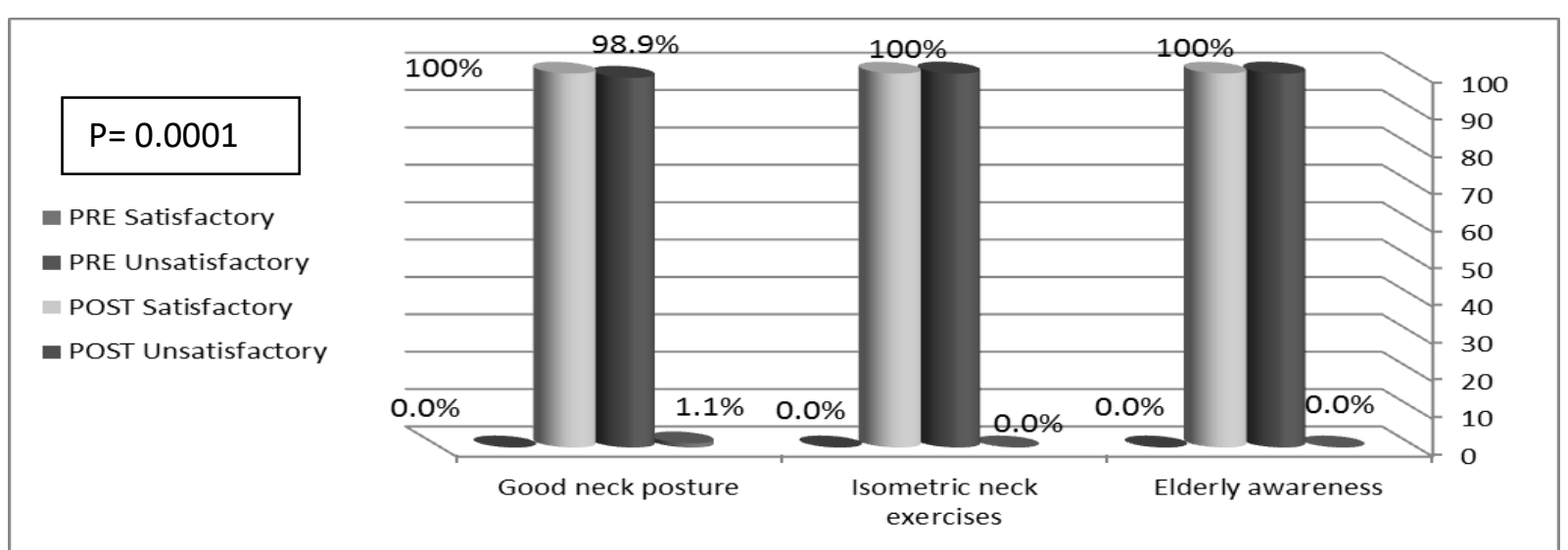

Figure (2): Distribution of studied elderly throughout program phases according to elderly awareness, isometric neck exercise and good neck posture in outpatient clinic of Rheumatology and Rehabilitation Department at Assiut University Hospital 2019, (N: 189).

Table (2): The Northwick Park Neck Pain Questionnaire (NPQ) levels pre and post isometric neck exercise and good neck posture program in outpatient clinic of Rheumatology and Rehabilitation Department at Assiut University Hospital 2019, (N: 189).

\begin{tabular}{|l|c|c|c|c|}
\hline \multirow{2}{*}{$\begin{array}{c}\text { Northwick Park Neck Pain } \\
\text { Questionnaire (NPQ }\end{array}$} & $\begin{array}{c}\text { Study sample (Pre) } \\
(\mathbf{n = 1 8 9 )}\end{array}$ & $\begin{array}{c}\text { Study sample (Post) } \\
(\mathbf{n = 1 8 9})\end{array}$ & \multirow{2}{*}{ P -value } & \multirow{2}{*}{ F ratio } \\
\cline { 2 - 3 } & $\mathbf{M e a n} \pm$ SD & Mean \pm SD & & \\
\hline Pain Intensity & $2.39 \pm 0.51$ & $0.21 \pm 0.44$ & $0.0001 * * *$ & 37.705 \\
\hline Pain and Sleeping & $1.69 \pm 0.54$ & $0.18 \pm 0.39$ & $0.0001 * * *$ & 47.047 \\
\hline Pins - Needles - Numbness & $1.08 \pm 0.54$ & $0.03 \pm 0.18$ & $0.0001 * * *$ & 68.354 \\
\hline Duration of Symptoms & $1.92 \pm 0.72$ & $0.06 \pm 0.26$ & $0.0001 * * *$ & 110.575 \\
\hline Carrying & $2.02 \pm 0.81$ & $0.69 \pm 0.69$ & 0.0761 & 0.092 \\
\hline Reading and Watching TV & $1.66 \pm 0.51$ & $0.63 \pm 0.49$ & 0.0810 & 0.058 \\
\hline Working & $1.19 \pm 0.51$ & $0.08 \pm 0.28$ & $0.0001 * * *$ & 29.167 \\
\hline Social activity & $1.29 \pm 0.46$ & $0.03 \pm 0.16$ & $0.0001 * * *$ & 354.064 \\
\hline Driving & $1.81 \pm 0.74$ & $0.64 \pm 0.49$ & 0.099 & 2.821 \\
\hline Independent Samples Test & $* * *$ highly statistically significant. & &
\end{tabular}

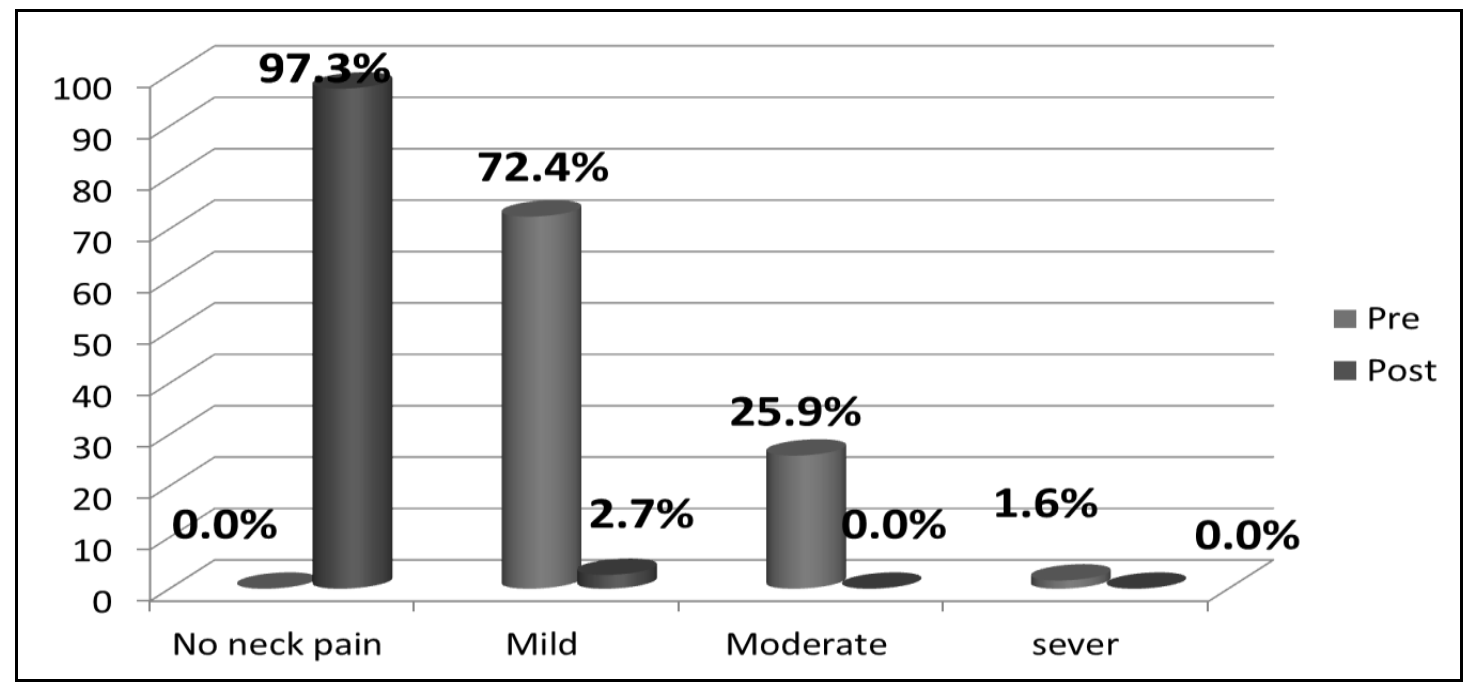

Figure (3): Comparison between pre and post isometric neck exercise and good neck posture program regarding to degrees of neck pain in outpatient clinic of Rheumatology and Rehabilitation Department at Assiut University Hospital 2019, (N: 189). 
Table (3): Relationship between socio-demographic characteristics and NPQ (Pre \&Post program) of studied elderly in outpatient clinic of Rheumatology and Rehabilitation Department at Assiut University Hospital 2019, (N: 189).

\begin{tabular}{|c|c|c|c|c|c|c|c|}
\hline \multirow{3}{*}{ Items } & \multicolumn{3}{|c|}{ NPQ Pre program } & \multicolumn{3}{|c|}{ NPQ Post program } & \multirow{3}{*}{$\mathbf{P 2}$} \\
\hline & $\begin{array}{l}\text { Mild } \\
\text { (137) }\end{array}$ & $\begin{array}{l}\text { Moderate } \\
\text { (49) }\end{array}$ & $\begin{array}{c}\text { Severe } \\
\text { (3) }\end{array}$ & $\begin{array}{l}\text { No pain } \\
(\mathrm{N}=184)\end{array}$ & $\begin{array}{c}\text { Mild } \\
(\mathrm{N}=5)\end{array}$ & \multirow[t]{2}{*}{ P 1} & \\
\hline & \multicolumn{3}{|c|}{ No. $(\%)$} & \multicolumn{2}{|c|}{ No. $(\%)$} & & \\
\hline \multicolumn{8}{|l|}{ Age } \\
\hline $60-65$ yrs. & $109(57.6)$ & $41(21.7)$ & $3(1.6)$ & $149(78.8)$ & $4(2.1)$ & \multirow{2}{*}{$0.003 * *$} & \multirow{2}{*}{$0.0001 * * *$} \\
\hline $66-70$ yrs. & $28(14.8)$ & $8(4.2)$ & $0(0.0)$ & $35(18.5)$ & $1(0.5)$ & & \\
\hline \multicolumn{8}{|l|}{ Gender } \\
\hline Male & $36(19.0)$ & $32(16.9)$ & $3(1.6)$ & $66(34.9)$ & $5(2.6)$ & \multirow{2}{*}{$0.0001 * * *$} & \multirow{2}{*}{$0.007^{* *}$} \\
\hline Female & $101(53.4)$ & $17(9.0)$ & $0(0.0)$ & $118(42.4)$ & $0(0.0)$ & & \\
\hline \multicolumn{8}{|l|}{ Residence } \\
\hline Urban & $51(27.0)$ & $17(9.0)$ & $2(1.05$ & $68(36.0)$ & $2(1.05)$ & \multirow{2}{*}{0.0536} & \multirow{2}{*}{0.612} \\
\hline Rural & $86(45.5)$ & $32(16.9)$ & $1(0.5)$ & $116(61.3)$ & $3(1.6)$ & & \\
\hline \multicolumn{8}{|l|}{ Marital status } \\
\hline Married & $117(61.9)$ & $39(20.6)$ & $2(1.05)$ & $154(81.4)$ & $4(2.1)$ & \multirow[t]{2}{*}{0.466} & \multirow{2}{*}{0.596} \\
\hline Widowed & $20(10.5)$ & $10(5.3)$ & $1(0.5)$ & $30(15.7)$ & $1(0.5)$ & & \\
\hline \multicolumn{8}{|c|}{ Education Level } \\
\hline Illiterate & $78(41.2)$ & $31(16.4)$ & $1(0.5)$ & $107(56.6)$ & $3(1.6)$ & \multirow{4}{*}{0.290} & \multirow{4}{*}{0.846} \\
\hline read and write & $15(7.9)$ & $1(0.5)$ & $0(0.0)$ & $16(8.5)$ & $0(0.0)$ & & \\
\hline Basic education & $15(7.9)$ & $6(3.2)$ & $0(0.0)$ & $20(10.5)$ & $1(0.5$ & & \\
\hline university degree & $29(15.3)$ & $11(5.8)$ & $2(1.05)$ & $41(21.7)$ & $1(0.5$ & & \\
\hline \multicolumn{8}{|c|}{ Job before retirement } \\
\hline Employee & $29(15.3)$ & $11(5.8)$ & $2(1.05$ & $41(21.7)$ & $1(0.5)$ & \multirow{5}{*}{$0.0001 * * *$} & \multirow{5}{*}{0.109} \\
\hline Worker & $7(3.7)$ & $5(2.6)$ & $0(0.0)$ & $11(5.8)$ & $1(0.5)$ & & \\
\hline Farmer & $12(6.3)$ & $18(9.5)$ & $1(0.5)$ & $29(15.3)$ & $2(1.05)$ & & \\
\hline Free business & $7(3.7)$ & $4(2.1)$ & $0(0.0)$ & $10(5.3)$ & $1(0.5)$ & & \\
\hline Housewife & $82(43.4)$ & $11(5.8)$ & $0(0.0)$ & $93(49.2)$ & $0(0.0)$ & & \\
\hline \multicolumn{8}{|c|}{ Job after retirement } \\
\hline don't work & $10(5.3)$ & $5(2.6)$ & $2(1.05)$ & $16(8.5)$ & $1(0.5)$ & \multirow{5}{*}{$0.0001 * * *$} & \\
\hline Worker & $7(3.7)$ & $5(2.6)$ & $0(0.0)$ & $11(5.8)$ & $1(0.5)$ & & \\
\hline Farmer & $12(6.3)$ & $18(9.5)$ & $1(0.5)$ & $29(15.3)$ & $2(1.05$ & & 0.109 \\
\hline Free business & $7(3.7)$ & $4(2.1)$ & $0(0.0)$ & $10(5.3)$ & $1(0.5)$ & & \\
\hline Housewife & $107(56.6)$ & $11(5.8)$ & $0(0.0)$ & $118(62.4)$ & $0(0.0)$ & & \\
\hline & & & erson Su & ported & & & \\
\hline Husband/wife & $122(64.5)$ & $44(23.3)$ & $2(1.05)$ & $164(86.7)$ & $4(2.1)$ & & \\
\hline Son & $4(2.1)$ & $3(1.6)$ & $1(0.5)$ & $7(3.7)$ & $1(0.5)$ & 0.085 & 0.181 \\
\hline Daughter & $11(5.8)$ & $2(1.05$ & $0(0.0)$ & $13(6.9)$ & $0(0.0)$ & & \\
\hline
\end{tabular}

Table (1): Cleared that $81.0 \%$ of the studied elderly aged $(60$ - < 65) years \& $62.4 \%$ of them were female. Figure (1): Showed that $55.0 \%$ of the studied elderly had hypertension, while $37.0 \%$ of them suffering from diabetes

Figure (2): Cleared that there was a highly statistically significant difference between pre and post-program related to elderly awareness, isometric neck exercises and good neck posture $(\mathrm{p}=0.0001)$

Table (2): Revealed that there was a highly statistically significant difference between pre and post isometric neck exercise and good neck posture program according to the NPQ in pain intensity, pain and sleeping, pins, needles, numbness, duration of symptoms, working and social activity $(\mathrm{p}=0.0001)$ while there is no significant difference between pre and post- program related to carrying, reading and watching TV and driving $(\mathrm{P}$-value $=0.0761,0.0810$, 0.099) respectively.

Figure (3): Showed that $72.4 \%$ of the studied elderly had mild neck pain and about one quarter of them had moderate pain in pre-test while after implementing 
isometric neck exercise and good neck posture program, the vast majority of them had no neck pain.

Table (3): Revealed that there was statistical significance difference between age, gender, job before and after retirement and NPQ in pretest with $\mathrm{P}=0.003,0.0001,0.0001$, respectively. While there was no statistical significance difference regarding educational level and job before and after retirement in posttest $\mathrm{p}=0.846,0.109$ respectively.

\section{Discussion}

Neck pain is a major cause of morbidity and disability in everyday life in many countries. It has an impact on the individual's physical, social, and psychological well-being. In addition, with the increasing aging population of medium- and low-income countries, the prevalence of neck pain will grow significantly in the coming decades (Genebra, et al., 2017). Moreover (El Laithy \& Fouda, 2018) documented that neck pain prevalence ranges from $14.2 \%$ to $71 \%$ in the general population in Egypt at some time in their lives and it was more prevalent among women. Therefore the present study was implemented to evaluate the efficacy of maintaining good posture and neck exercise on reducing cervical pain among elderly patients.

The present study showed that the majority of studied patients aged $(60-<65)$ years, with mean age $62.48 \pm$ 3.43 and cervical pain was more common in females than males as about three fifth of the studied sample were female, this may be due to elderly female more occupied with other different duties than males. This is similar to study done by Son et al., (2013) about prevalence and risk factor of neck pain in elderly Korean community residents and reported that mean age of the studied populations is $61.4 \pm 8.75$ and $57.46 \%$ of them were female.

On the other hand, Azadi, et al., (2019) who study effect of 12-week neck, core, and combined stabilization exercises on the pain and disability of elderly patients with chronic non-specific neck pain: a clinical trial observed that $60.1 \%$ of participants were male with a mean \pm SD age of $68.28 \pm 4.61$ years.

The current study finding explained that about two thirds of elderly patients lived in rural areas. This may be due to most elderly occupied with hard work like agriculture that may effect on their neck posture and lead to pain. This comes in accordance with De Freitas Pereira, et al., (2014) who studied socioeconomic and demographic profile of older elderly users of primary health unit and found that $60 \%$ of elderly people live in rural areas.

Regarding to marital status, it was observed that majority of the studied elderly were married and more than half of them suffering from hypertension. This agree with the result of Son et al., (2013) who found that $83.4 \%$ of the participants were married and diabetes and hypertension are common health problems in the elderly with neck pain.

Concerning to level of education, it was apparent that more than half of the studied sample were illiterate and less than one quarter of them had a university education. This related to that educated people seeking help as early as possible in reverse to illiterate ones. These findings were consistent with that reported by Silva, et al., (2018) that $73.9 \%$ of the elderly had none or less than eight years of study

The present study demonstrated that there was a highly statistically significant difference between pre and post elderly knowledge $(\mathrm{p}=0.0001)$. A possible explanation could be that the majority of elderly patients are young old and able to restore their information. This supported the result of study conducted by (Shin, \& Kim, 2013) who reported that the experimental group reported significant improvement in their knowledge of exercise compared with the control group.

The present study showed that there was a highly statistically significant difference between pre and post-practice isometric neck exercises $(\mathrm{p}=0.0001)$, this may be related to that steps of exercise was simple for elderly patient to do. This is similar to Azadi, et al., (2019) who founded that neck exercises significantly reduced neck pain over time $(\mathrm{P}=0.008)$.

Similarly, Akodu et al., (2018) reported that neck stabilization exercise significantly reduce the severity of pain in patients with chronic neck pain $(\mathrm{P}=0.001)$. And Alpayci, \& Ilter, (2017) documented that the reduction in neck pain was about twice in the exercise group compared with the control group $(P=0.001)$.

Moreover the finding of the present study was in the same line with the following finding of (Bansode\& Hande, 2016, Hassan et al., 2016, Khan et al., 2014 \& Sowmya, 2014) who reported that isometric exercise is significantly effective on reducing neck pain.

In the present study there was statistical significant difference between pre and post-practice related to good neck posture $(\mathrm{p}=0.0001)$, this may be due to patients persuade that posture plays an important role in relieving their pain and it is easy for them to maintain it. This agrees with study conducted by (Mohankumar \& yie, 2017) who showed that, there was a significant difference in the neck posture between chronic neck pain patients and age matched pain free persons. Thus, postural changes in the neck need to be considered during therapeutic intervention of patients with chronic neck pain. Also Cramer et al., (2018) documented improvements in postural awareness are longitudinally associated with reduced pain in patients with spinal pain. $(\mathrm{P}=0.001)$ 
Regarding to pre and post program results on the Northwick Park Neck Pain Questionnaire, there is a highly significant difference throughout program phases according to pain intensity, pain and sleeping, pins, needles, numbness, duration of symptoms, working and social while there is no significant difference between pre and post- program related to carrying, reading and watching TV and driving, this may be related to the inability of elderly patients to carry heavy object and the discomfort they feel in their neck with driving in pre and post program. This agrees with Gonzalez et al., (2011) who reported that there was a highly significant difference between before and after physiotherapy treatment according to pain intensity, pain and sleeping, pins, needles, numbness, duration of symptoms, working and social ( $p=0.0001)$ and there is no significant difference related to driving, while disagree with him regarding to carrying, and reading. In my opinion, this reflects the simplest of isometric exercise and good neck posture steps which resulting in the compliance of participants elders with it.

In the current study, it was observed that less than three quarters of the studied elderly had mild neck pain, and about one quarter of them had moderate pain, while after isometric neck exercise and good neck posture program, the vast majority of them hadn't neck pain as patients was in compliance with the exercise for three month. This agrees with Raza et al., (2019) who found that $84 \%$ of participants were suffering from mild neck pain and $16 \%$ moderate pain.

On the other hand, these results differ from that recorded by Mullai, (2016) who found that in the experimental group, majority $(60.0 \%)$ of the sample had moderate level of neck pain and $40.0 \%$ of them had mild level of neck pain in pretest. In posttest $66.7 \%$ of the samples had mild level of neck pain and $33.3 \%$ of them had no pain.

The present study pointed that there was statistical significance difference between age, gender with Northwick Park Neck Pain Questionnaire (NPQ) in pretest and posttest, and job before and after retirement with NPQ in pretest $\mathrm{P}=0.0001$. While there was no statistical significance difference regarding educational level and job before and after retirement in posttest $\mathrm{p}=0.846,0.109$ respectively. In my opinion, this may be related to that elderly participants compliance with isometric neck exercise and maintain good neck posture during the day.

\section{Conclusion}

The present study concluded that cervical pain is common in female than male and more prevalent among elderly people who had low educational level and came from rural areas, there was lack of elderly knowledge about importance of good neck posture and isometric neck exercise and conducted that reducing cervical pain and improving awareness of patients after implementing posture awareness and neck exercise program

\section{Recommendations}

Based on the result of the current study the following is recommended that

- Implementation of isometric exercise and good neck posture among elderly population should be expanded as a community based intervention.

- Health care professionals require access to current education on evidence based neck pain management to ensure that patients receive the most recent health advice

- A structured teaching program can be conducted to assess the effectiveness of isometric exercise in improving the neck muscle strength among elderly patients.

- Provide the Rheumatology and Rehabilitation unit with health educational program about neck posture and isometric exercise to increase awareness of elderly patients with cervical pain.

\section{References}

1. Aguirre, M., Rodríguez, M., Clarett, M., Iribarne, J., Martínez, M., Battistotti, R., \& Orsini, E., (2013): Cultural adaptation and Argentine validation of the Northwick Park Neck Pain Questionnaire in the hospitals of the Autonomous City of Buenos Aires. Revista de la Facultad de Ciencias Medicas (Cordoba, Argentina), 70(2), 76-82

2. Akodu A., Odunsi F., \& Giwa S., (2018): Effects of- Neck Stabilization Exercise on Pain, Disability, Craniovertebral Angle and Psychological Status in Patient with NonSpecific Chronic Neck Pain. JRCRS. 6(1):1015.

3. ALI A., (2015): age related changes in cervical spine, Int J Pharm Bio Sci, 6(2): 760 769.

4. Alpayci, M., \& Ilter, S., (2017): Isometric exercise for the cervical extensors can help restore physiological lordosis and reduce neck pain: a randomized controlled trial. American journal of physical medicine \& rehabilitation, 96(9), 621-626.

5. Azadi, F., Nabi, A., Marioryad, H., Alimohammadi, M., Karimpour, V., \& Poursadeghiyan, M., (2019): Effect of 12Week Neck, Core, and Combined Stabilization Exercises on the Pain and Disability of Elderly 
Patients With Chronic Non-specific Neck Pain: A Clinical Trial, 13( 5 ): $614-616$

6. Bansode, A., \& Hande, D., (2016): Effectiveness of isometric neck exercises, stretching and ergonomics over ergonomic alone for neck pain in physiotherapists. Imperial Journal of interdisciplinary research, 2, 36-40.

7. Central Intelligence Agency, (2019): Egypt Demographics Profile 2019, Available at https://www.indexmundi.com/egypt/demograp hics_profile.html

8. Cramer H., Mehling W., Saha F., Dobos G., \& Lauche R., (2018): Postural awareness and its relation to pain: validation of an innovative instrument measuring awareness of body posture in patients with chronic pain. BMC musculoskeletal disorders, 19(1), 109.

9. De Freitas Pereira, L., Lenardt, M., Michel, T., \& Carneiro, N., (2014): Socio- economic and demographic profile of older elderly users of primary health unit. Cogitare Enferm, 19(4), 651-7

10. El Laithy, M., \& Fouda, K., (2018): Effect of post isometric relaxation technique in the treatment of mechanical neck pain. Physical Therapy and Rehabilitation, 5(1), 20

11. Geiger, C., \& Devereaux, M. (2017): An Approach to the Patient with Neck Pain. Medical Research Archives, 5(5)

12. Genebra, C., Maciel, N., Bento, T., Simeão, S., \& De Vitta, A., (2017): Prevalence and factors associated with neck pain: a population-based study. Brazilian journal of physical therapy, 21(4), 274-280

13. Glowacki, D., (2015): Effective pain management and improvements in patients' outcomes and satisfaction. Critical care nurse, 35(3), 33-41.

14. Gonzalez, T., Balsa, A., de Murieta, J., Zamorano, E., González, I., \& MartinMola, E., (2011): Spanish version of the Northwick Park Neck Pain Questionnaire: reliability and validity. Clinical and experimental rheumatology, 19(1), 41-46

15. Hassan, W., Malik, S., Gondal, J., Akhtar, S., Zafar, A., Anmol, S., Mubeen, I., \& Khali, F., (2016): comparison of effectiveness of isometric exercises with and without stretching exercises in non specific cervical pain. International Journal of Physiotherapy, 3(3), 371-375.

16. Jayabal, T., (2018): Effect of combination of isotonic and isometric training with asanas practices on selected bio motor variables of adolescent boys. Asian Journal of
Multidimensional Research (AJMR), 7(2), 1005-1009

17. Khan, M., Soomro, R., \& Ali, S., (2014): The effectiveness of isometric exercises as compared to general exercises in the management of chronic non-specific neck pain. Pak J Pharm Sci, 27(5), 1719-22

18. Leak A., Cooper J., Dyer S., Williams K., Turner-Stokes L., \& Frank A., (1994): The Northwick Park Neck Pain Questionnaire, devised to measure neck pain and disability. Rheumatology, 33(5), 469-474

19. Maiers M., Bronfort G., Evans R., Hartvigsen J., Svendsen K., Bracha Y., Schulz C., Schulz K., \& Grimm R., (2014): Spinal manipulative therapy and exercise for seniors with chronic neck pain, The Spine Journal, 14(9), 1879-1889.

20. McDonnell, M., \& Lucas, P., (2012): Cervical spondylosis, stenosis, and rheumatoid arthritis. Rhode Island Medical Journal, 95(4), 105

21. Mohankumar, P., \& Yie, L., (2017): head and neck posture in young adults with chronic neck pain, International Journal of Recent Advances in Multidisciplinary Research, Vol. 04, Issue 11, pp.2946-2951.

22. Mullai, K., (2016): A study to assess the effectiveness of isometric exercise on neck pain and functional disability among computer professionals at selected it companies, Chennai (Doctoral dissertation, MA Chidambaram College of Nursing, Chennai)

23. Pascucci M., Chu N., \& Leasure A., (2012): Health promotion for the oldest of old people. Nursing Older People. 24(3), 22-28. Available at https://www.ncbi.nlm.nih.gov/pubmed/225677 72

24. Pillastrini, P., de Lima E., Sá Resende, F., Banchelli, F., Burioli, A., Di Ciaccio, E., Guccione, A., \& Vanti, C., (2016): Effectiveness of global postural re-education in patients with chronic nonspecific neck pain: randomized controlled trial. Physical therapy, 96(9), 1408-1416

25. Raza M., Khalid, M., \& Javed, M., (2019): Prevalence and Intensity of Neck Pain in Sewing Machine Operators, Journal of Physical Therapy.

26. Shin, K., \& Kim, J., (2013): Corrigendum: the effects of exercise program on knowledge and attitude of exercise and depression in lowincome elderly women. Journal of Korean Academy of Nursing, 43(1), 143-143 
27. Silva, P., Santos, F., Soares, S., \& Silva, L., (2018): Socio demographic and clinical profile of elderly persons accompanied by Family Health teams under the gender perspective/Perfil socio demográfico e clínico de idosos acompanhados por equipes de Saúde da Família sob a perspectiva do gênero. Revista de Pesquisa: Cuidado é Fundamental Online, 10(1), 97-105

28. Son, K., Cho, N., Lim, S., \& Kim, H., (2013): Prevalence and risk factor of neck pain in elderly Korean community residents. Journal of Korean medical science, 28(5), 680-686

29. Sowmya M., (2014): Isometric Neck Exercises versus Dynamic Neck Exercises in Chronic Neck Pain, IOSR Journal of Nursing and Health Science (IOSR-JNHS) 3(2): 32-43. 